\title{
Editorial
}

\section{Joakim Goldhahn*}

\section{Science in a Time When the World Is Growing Apart and Coming Together}

https://doi.org/10.1515/opar-2020-0128

received March 10, 2021; accepted March 10, 2021.

Challenging times. 2020 was a year like no other. A constant flow of alarming news about an escalating climate crisis. The hottest year on record. Polar ices and glaciers are melting, some bringing new objects from the past into the world again. Ecocides. Animals, birds, and bugs are becoming extinct at a rate that we have never seen before. On top of that, Covid-19, like a flash from a blue sky, hit us all with shock. Lockdowns and the fear of becoming sick, losing family and kin, project collaborators and collegian friends. Too many lost their lives; others struggle to get back on track. For many people around the world, 2020 will be remembered as a year of mourning.

Covid-19 did not pass the academic or archaeology field without notice. Education, conferences, and research projects were cancelled or put on ice. Many universities that are dependent on international students took a hard economic dip in 2020. For some, it will take years to recover. Hard times. As a response, redundancies and the cessation of hiring staff. All possible loose ends are cut. Early career scholar's opportunities seem to vanish by the minute. Academics in solitudes tend to write more, and we see an increase in submitted journal articles generally, and this is also the case for Open Archaeology, something that we welcome. At the same time, there are alarming indications worldwide that rooted gender biases within the academic field are growing again. This also seems to be the case for publications, manifested through an increasing number of articles first authored by men. We at Open Archaeology will oversee this trend. Moreover, reports from Sweden indicate that students' well-being is decreasing. Similar trends have been noted worldwide. Many of the students feel detached, alone, and stressed about their education and future. 2020 was a year like no other.

And amid the turmoil, the show must go on.

Now, writing in 2021, there is some light at the end of the tunnel. Vaccines prove their value, and the numbers of sick and passing are falling. Slowly. At the same time, working from home, we adapt and connect in new ways: online meetings and conferences, teaching, disputations, and even after-work gatherings on Friday afternoons. After the first blast of isolation, we witnessed how the world slowly started to grow together in a new and somewhat exciting way. Some have even proposed that this will be "the new normal." However, the gaze of "an old-time" conference or symposia has never been more desiring. Hold on. There is light at the end of the tunnel.

That said, we at Open Archaeology are looking forward to a busy 2021 of publishing research from all over the world. The numbers of submitted articles are rising, and we are also happy to see that the scope of published articles in Open Archaeology 2020 and submitted articles under review is widening. Our partnership with the international conferences “Meso'2020," held online from Toulouse in France last September, on publishing its proceedings (coordinating editors: Thomas Perrin, Benjamin Marquebielle, Sylvie Philibert, and Nicolas Valdeyronas), pledges that our readers can look forward to an exciting year. There are also calls out for several interesting special topical issues of Open Archaeology, including "Archaeological Practice on Shifting Grounds" (coordinating editors: Åsa Berggren and Antonia DavidovicWalther), "Creativity and Automation: Sharing 3D Visualization Practices in Archaeology" (coordinating editors: Loes Opgenhaffen, Martina Revello Lami, and Hayley Mickleburgh), "At the Crossroads of the Mediterranean: Malta and the Central Mediterranean During the Roman Period" (coordinating editors: David Cardona, Davide Tanasi, and Robert

*Corresponding author: Joakim Goldhahn, Kimberley Foundation Ian Potter Chair in Rock Art, School of Social Sciences, Centre for Rock Art Research + Management, The University of Western Australia, 35 Stirling Highway, 6009, Perth, Australia, E-mail: joakim.goldhahn@uwa.edu.au 
Brown), an issue in cooperation with "The 1st Conference on the Early Neolithic of Europe" (coordinating editors: Ferran Borrell, Ignacio Clemente, Miriam Cubas, Juan J. Ibáñez, Niccolò Mazzucco, Ariadna Nieto, Marta Portillo, Xavier Terradas and Silvia Valenzuela), and "The Black Gold That Came from the Sea: Advances in the Studies of Obsidian Sources and Artifacts of the Central Mediterranean Area" (coordinating editors: Franco Italiano, Franco Foresta Martin, and Maria Clara Martinelli). Information about these and the future special topical issues can be found on the journal's home page.

Last but not least, we at Open Archaeology wish our readers a healthy and productive year. Stay safe. Keep socially connected. Reach out to your students, colleagues, and friends. Hopefully soon there will be an end to "this new normal." Let’s wish that the light in the tunnel keeps getting brighter...

Joakim Goldhahn Editor-in-Chief 